\title{
Forecast of Healthcare Facilities and Health Workforce Requirements for the Public Sector in Ghana, 2016-2026
}

\author{
James Avoka Asamani ${ }^{*}$, Margaret M. Chebere ${ }^{1}$, Pelham M. Barton ${ }^{2}$, Selassi Amah D’Almeida ${ }^{3}$, Emmanuel \\ Ankrah Odame ${ }^{4}$, Raymond Oppong ${ }^{2}$
}

\begin{abstract}
Background: Ghana is implementing activities towards universal health coverage (UHC) as well as the attainment of the health-related Sustainable Development Goals (SDGs) by the health sector by the year 2030. Aside lack of empirical forecast of the required healthcare facilities to achieve these mandates, health workforce deficits are also a major threat. We therefore modelled the needed healthcare facilities in Ghana and translated it into year-by-year staffing requirements based on established staffing standards.

Methods: Two levels of modelling were used. First, a predictive model based on Markov processes was used to estimate the future healthcare facilities needed in Ghana. Second, the projected healthcare facilities were translated into aggregate staffing requirements using staffing standards developed by Ghana's Ministry of Health $(\mathrm{MoH})$.

Results: The forecast shows a need to expand the number/capacity of healthcare facilities in order to attain UHC. All things being equal, the requisite healthcare infrastructure for UHC would be attainable from 2023. The forecast also shows wide variations in staffing-need-availability rate, ranging from $15 \%$ to $94 \%$ (average being $68 \%$ ) across the various staff types. Thus, there are serious shortages of staff which are worse amongst specialists.

Conclusion: Ghana needs to expand and/or increase the number of healthcare facilities to facilitate the attainment of UHC. Also, only about $68 \%$ of the health workforce (HWF) requirements are employed and available for service delivery, leaving serious shortages of the essential health professionals. Immediate recruitment of unemployed but qualified health workers is therefore imperative. Also, addressing health worker productivity, equitable distribution of existing workers, and attrition may be the immediate steps to take whilst a long-term commitment to comprehensively address HWF challenges, including recruitments, expansion and streamlining of HWF training, is pursued.

Keywords: Health Workforce Forecasting, Health Modelling, Health Resources for Health, Healthcare Facilities, Universal Health Coverage

Copyright: (๑) 2018 The Author(s); Published by Kerman University of Medical Sciences. This is an open-access article distributed under the terms of the Creative Commons Attribution License (http://creativecommons.org/licenses/ by/4.0), which permits unrestricted use, distribution, and reproduction in any medium, provided the original work is properly cited.

Citation: Asamani JA, Chebere MM, Barton PM, D'Almeida SA, Odame EA, Oppong R. Forecast of healthcare facilities and health workforce requirements for the public sector in Ghana, 2016 - 2026. Int J Health Policy Manag. 2018;7(11):1040-1052. doi:10.15171/ijhpm.2018.64
\end{abstract}

Article History:

Received: 8 September 2017

Accepted: 8 July 2018

ePublished: 7 August 2018

\section{Key Messages}

Implications for policy makers

- Using agreed staffing standards/norms to estimate aggregate health workforce (HWF) requirements for a country could produce realistic projections to guide HWF investments, recruitment, deployment and retention strategies.

- On average, there is about $32 \%$ shortage of the required HWF in Ghana. The shortage is however highest (75\%) amongst laboratory workers and lowest (6\%) amongst auxiliary nurses. Policy-makers in Ghana should reprioritise the training and recruitment of frontline health workers taking into account the emerging evidence.

- Policy-makers in Ghana should give specialist training the needed priority in terms of funding to address the serious specialists' shortage.

Implications for the public

This paper focused on estimating the number of health facilities with corresponding health workforce (HWF) requirements for evidence-informed planning in Ghana. Such evidence would complement efforts to expand service coverage for all populations. Public advocacy is needed to shape the policy agenda for equitable investment in the production and retention of all required categories of the HWF. 


\section{Background}

Healthcare delivery across the world, especially in lowand middle-income countries is aimed at universal health coverage (UHC) and most recently, the Sustainable Development Goals (SDGs) by the year 2030. ${ }^{1}$ Central to the achievement of both aspirations is the critical role of a health workforce (HWF), also termed as human resources for health (HRH). ${ }^{2}$ Consequently, human resources for health planning (HRHP) has been identified as an important process towards the attainment of SDG 3 particularly target 3.c that seeks to substantially increase the recruitment, development, training and retention of the health workforce (HWF). In 2015, the World Health Organization (WHO) in consultation with various stakeholders developed a Global Strategy on HWF Workforce 2030 to respond to HWF challenges across health systems. ${ }^{3}$ It also reinforced the view that the quality and cost of healthcare delivery largely depends on the availability and equitable distribution of health personnel. ${ }^{4}$

The process of HRHP involves determining and putting in place strategies to obtaining the required number of HWF with the right skills and competency; and their appropriate deployment to deliver timely and affordable services that address population health needs. ${ }^{5,6}$ HWF forecasting is one of the initial elements of a broader HRHP. ${ }^{7}$ It encompasses taking stock of available HWF, and estimating current and future HWF needed and comparing with the expected supply. This helps to establish demand and supply gaps (labour market gaps) or current need-availability gaps., ${ }^{2,7}$

There are two sides to HWF forecasting which are HWF supply and HWF demand forecasting. ${ }^{8}$ HWF supply side forecasting involves determining the inflow and outflow of health workers from the current workforce. The inflow depends on the training capacity and immigration, whilst outflow/attrition depends on retirements, deaths, resignations, emigration and dismissals. ${ }^{2}$ On the other hand, HWF demand side forecasting, which is the thrust of this paper, involves determining the current and future HWF requirements. Commonly used approaches to HWF demand side forecasting include population health needs or epidemiological approach; service demand or utilisation approach; service targets approach; staff-to-population ratios approach; econometrics approach; and health service development analysis (HeSDA)/staffing standards (also known as facilitybased) approach. ${ }^{2,4,6,9,10}$ A comprehensive description of these approaches, including their advantages and disadvantages abounds in the literature. ${ }^{2,7,11}$ These models tend to differ in their level of transparency, data requirements and outputs. Therefore, the choice of a particular approach is often informed by the capacity of the analysts, availability of data and the nature of the healthcare system ${ }^{4}$ as there appear to be no method that is superior in all circumstances.

Fakhri and colleagues ${ }^{12}$ compared three methods for HWF forecasting that include the population-needs method, the service-utilisation approach and the service-targets method. The authors reported that the population-needs method yielded a staffing requirement that was $44 \%-57 \%$ higher compared to the service utilisation approach and the servicetargets method yielded $10 \%-21 \%$ higher staffing requirements than the service utilisation method.

Also, a Thai study ${ }^{10}$ that compared the projections of future demand for nurses using the staff-to-population ratio, population health needs, and HeSDA showed that although some variation in the estimates was generally seen amongst the three methods, the difference decreased with increasing time horizon (for example, reducing from 40000 in 2005 to just 10000 by 2015) and the estimates converged at the end of the forecast period. This partly suggests that some of the HRH forecasting approaches tend to converge or complement each other when used for long term planning.

HRHP in many countries is often done on ad hoc basis with poor data and of varying quality and horizon of planning. ${ }^{2}$ The resultant effects are defective HWF policies that lead to periodic HWF excesses and shortages. An excess in $\mathrm{HRH}$ results in economic inefficiencies and supplier-induced demand ${ }^{2,13}$ while HWF shortage is associated with avoidable medical errors, poor and inequitable healthcare delivery. ${ }^{2}$

As espoused in Ghana's policies, strategic documents and operational plans, the main goal of the health sector is to build a robust health system towards the attainment of UHC. ${ }^{14-16}$ Over the years, the government of Ghana has invested in healthcare infrastructure and health insurance coverage in a bid to improve access to, and bridge inequalities in, healthcare delivery. However, there has not been an empirical forecast of the number and types of health facilities required to attain UHC so as to guide infrastructural investment and distribution of HWF.

Ghana has made some progress in training and retaining HWF in recent years which has culminated in almost doubling the HWF density from 1.07 in 2005 to 2.14 in $2015 .{ }^{17,18}$ Some reports and published literature, however, show that the available HWF do not meet international benchmarks. ${ }^{19-21}$ For instance, the work of Scheffler and colleagues ${ }^{21}$ showed serious deficits in the number of physicians, nurses and midwives in Ghana by 2015, a concern corroborated by operational surveys and annual holistic assessment reports of the Ministry of Health (MoH), Ghana. ${ }^{22-25}$ As part of efforts to address the aforesaid challenges, the $\mathrm{MoH}$ developed staffing standards (also known as staffing norms) for healthcare facilities in the country ${ }^{26}$ based on a meta-analysis of individual health facilities' results of a country-wide staffing study using an evidence-based tool recommended by the WHO, known as Workload Indicators of Staffing Needs (WISN). ${ }^{27}$ Even though the staffing norms have been widely received by stakeholders and operationalised for deployment of newly recruited staff since 2014, the MoH's holistic assessment report of the health sector programme of work for 2013 recommended "... an analysis of the workforce requirements based on the newly developed staffing norm, and budget forecast ...."24 Such a forecast on a year-by-year basis would enhance effective annual planning and budgeting as well as promote responsive HWF policies. This paper focused on forecasting the healthcare facilities and HWF requirements for the public sector in Ghana. In so doing we sought to address the following questions:

1. How many health facilities are needed in the public health sector of Ghana to facilitate the attainment of UHC? 
2. Based on the projected health facilities, what would be the HWF requirements of the public health sector of Ghana on a year-by-year basis over the next decade?

3. What is the gap between current staffing levels and the required staffing needs of the public health sector of Ghana?

\section{Methods}

Introduction to Ghana's Healthcare Delivery Model

Ghana operates a multi-level public healthcare delivery system (Figure 1). The top tier healthcare delivery institutions are made of autonomous teaching hospitals (THs), which are national referral hospitals with a mandate for managing complex health problems, research and staff training. Each $\mathrm{TH}$ is linked with a university to enhance its functions.

There are also regional hospitals (RHs), which provide a secondary level of specialised healthcare and serve as referral centres for each of the ten political regions. The catchment population of RHs is about 1.2 million people.

At the district level, district (primary) hospitals (DHs) serve as referral centres and provide basic and emergency healthcare to populations of $100000-200000 .{ }^{17}$ Each district is further divided into health sub-districts which are served by health centres (HCs) that provide basic curative and preventive services covering up to 20000 population. In urban areas, their capacity is often enhanced and they are then known as polyclinics to serve populations larger than 20000 .

At the bottom of the hierarchy of health service delivery are the community-based health planning and services (CHPS) compounds/zones which is the main strategy for delivering basic primary healthcare at the community level. ${ }^{14}$ These are mandated to provide mainly preventive services and treatment of minor ailments with over-the-counter medications to populations up to 5000 or 750 households. In addition, there are public specialized hospitals, quasi government hospitals and private for profit hospitals and clinics.
Overview of Modelling Approach

The HeSDA and staffing norms, also known as facility-based approach was selected for Ghana's context. The HeSDA approach was deemed appropriate for this forecast because it has been shown to be relatively simple but methodologically fit-for-purpose in developing countries. ${ }^{7,10}$ It also accounts for the country's existing infrastructural capacity whilst allowing for incorporation of plans for future infrastructural and technological expansion, which are key variables in pragmatic HWF forecasts. In Ghana, the $\mathrm{MoH}$ has been desirous of forecasting the HWF requirements "within the framework of [the MoH's] agreed staffing norms." ${ }^{15}$ In the literature, Kolehmainen-Aitken ${ }^{7}$ have emphasised the importance of this approach, stating, "estimating HWF requirements is [should be] based on the acceptance of norms or standards... [even though] no optimally 'correct' standards exist" (p. 16).

This approach estimates future HWF requirements "from projected [number of] healthcare facilities and staffing norms [standards]." ${ }^{10}$ It allows analysts to model future developments of healthcare facilities (in terms of numbers and categories of facilities) based on which predetermined staffing standards are applied to generate aggregate HWF requirements at regional or national levels.

Two levels of modelling were employed to arrive at aggregate HWF requirements. First, Markov state-transition processes were used to forecast the number and categories of future healthcare facilities. MoH staffing norms were then used to translate the number and categories of future health facilities into HWF requirements. These two levels of modelling are described subsequently.

\section{Modelling the Number of Healthcare Facilities (Health Services Development) \\ Model Structure and Assumptions}

For the purpose of HWF allocation, publicly funded healthcare facilities are categorised based on their outputs and workload

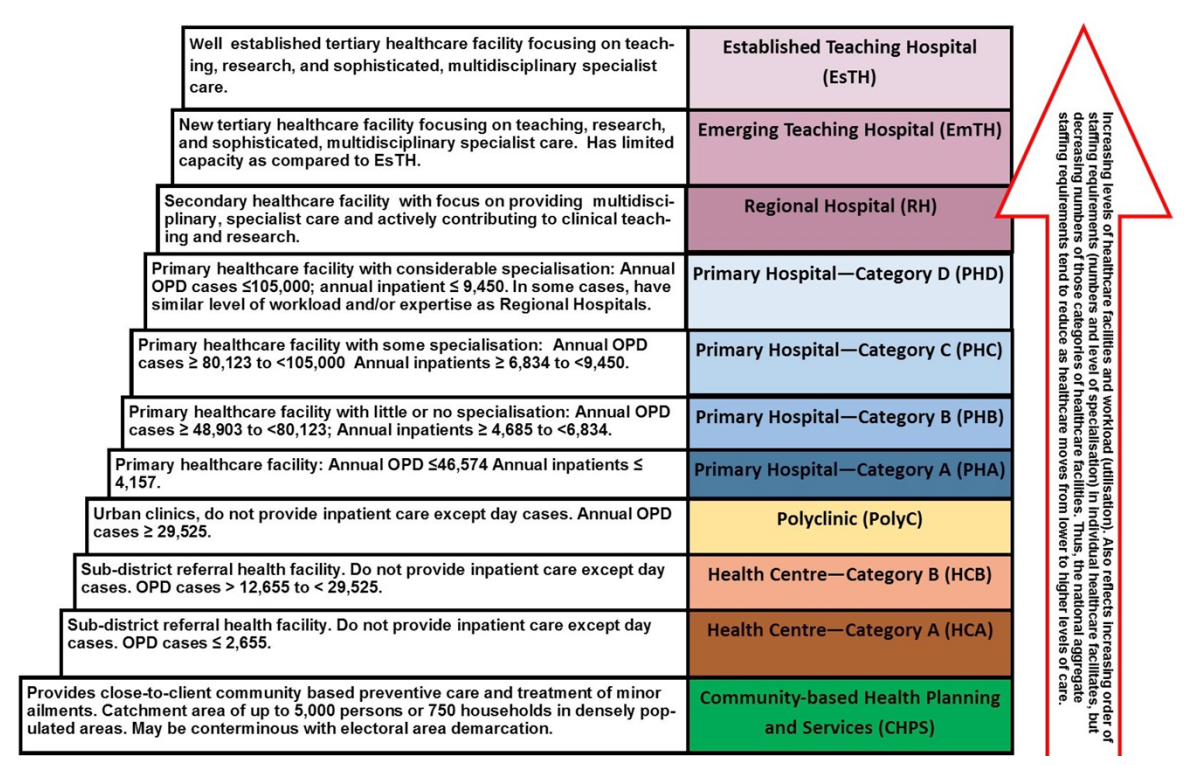

Figure 1. Categorisation of Public Healthcare Facilities in Ghana for Health Workforce (HWF) Allocation. Adapted from Staffing Norms MoH, 2015. 


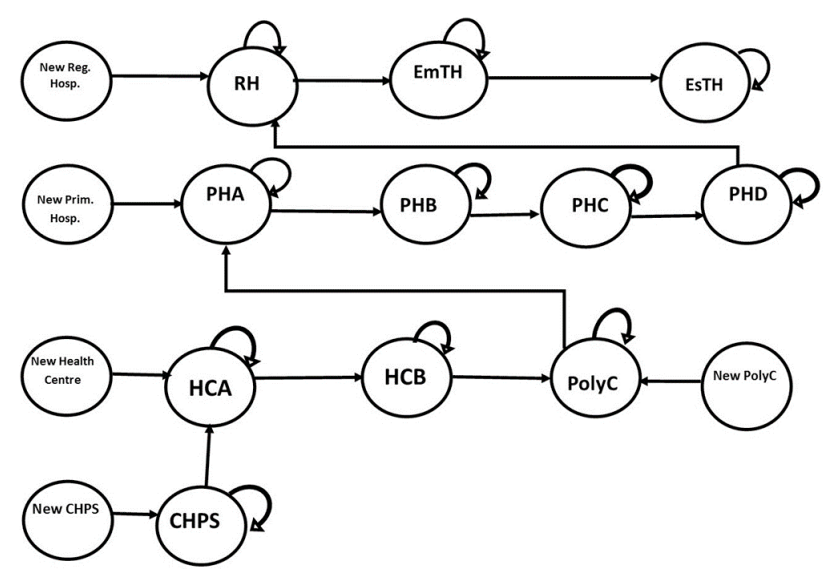

Figure 2. Structure of the Predictive Model for Healthcare Facilities in Ghana.

Source: Authors' construction.

Abbreviations: CHPS, community-based health planning and services; HCA, health centre in workload category A; $\mathrm{HCB}$, health centre in workload category B; PolyC, polyclinic; PHA, primary hospital in workload category A; PHB, primary hospital in workload category B; PHC, primary hospital in workload category C; PHD, primary hospital in workload category D; RH, regional hospital; EmTH, emerging teaching hospital; EsTH, established teaching hospital.

levels (Figure 2). As population and/or workload increases, lower level healthcare facilities would have to be upgraded to higher level categories to enhance their capacity and receive higher HWF allocation. ${ }^{15,26}$

This transition from one category of healthcare facilities to another is analogous to patients moving from one health state to another in typical Markov models as used in health economic evaluations. ${ }^{28,29}$ Therefore, Markov process was deemed appropriate for predicting the future development of health facilities. However, since annual planning cycle is a discrete-time process, half cycle correction was not applicable. The model deems each category of healthcare facilities as a 'state' in which there is a probability of transitioning to another 'state' or category of healthcare facility in the future depending on changes in their output and workload levels. Even though transitions from higher categories of healthcare facilities to lower ones are theoretically possible, we conservatively assumed that healthcare facilities can only transition from lower categories to the next higher ones or remain in the same category. This assumption is informed by experiences in the Ghanaian health sector that HWF is not usually withdrawn from healthcare facilities on the basis of a decreased utilisation in a particular year. It is further assumed that existing public healthcare facilities would not be closed down due to high unmet health needs. ${ }^{17}$

The model also takes into account government's ongoing projects or future plans of establishing new healthcare facilities or expanding existing ones. Figure 2 illustrates the predictive model structure.

\section{Time Horizon and Cycle Length}

The model was set up to run a cycle of one year for a 10-year forecast horizon. The 1-year cycle was informed by the fact that healthcare facilities' workload data is usually analysed on an annual basis to inform staff recruitment and distribution planning for the ensuing year. ${ }^{15} \mathrm{~A} 10$-year time horizon was chosen to coincide with the lifespan of key strategic policies and plans. ${ }^{30}$ It has also been suggested in the literature that HWF forecasts tend to lose their value beyond ten years due to the rapidly changing dynamics of the healthcare industry. ${ }^{4}$

\section{Transition Probabilities}

Decision analytic models (DAMs) are driven by transition probabilities, which are defined in this context as the likelihood that a healthcare facility would in the future move from one category or 'state' to the other. ${ }^{29}$ The transition probabilities was derived from routine data of healthcare facilities' utilisation (2011-2015) obtained from the District Health Information Management System database (DHIMS-2) of the MoH ${ }^{31}$ On a year-by-year basis from 2011 to 2015, each healthcare facility was assigned its appropriate workload category as set out in the MoH staffing norm (see Figure 1 for criteria). The number of transitions from one category of healthcare facility to another were analysed to derive transition probabilities with the aid of Microsoft ${ }^{\circledR}$ Excel (2016 version) and appropriate statistical formulae..$^{29,32,33}$ The derived transition probabilities are shown in Table 1.

\section{Existing Number of Healthcare Facilities and Transitions From One Category to Another}

The number of existing healthcare facilities in each of the ten regions of Ghana as of March, 2016 was taken from the Health Sector Holistic Assessment Report ${ }^{23}$ and the DHIMS-2 database. ${ }^{31}$ Ongoing and planned projects of establishing new healthcare facilities or expansion of existing ones were taken from various government sources. ${ }^{15,34,35}$ Data on the number of demarcated CHPS zones in various regions was based on extrapolation from the CHPS policy (1500 population or 750 households per CHPS zone) $)^{14}$ using population estimates (see equation I).

Based on the possible movements of health facilities from one workload category to another as depicted in the model structure (Figure 2) and the associated transition probabilities (Table 1), the following set of formulae (equations II-XI) was 
Table 1. Model Input Parameters

\begin{tabular}{|c|c|c|c|c|}
\hline Parameter & & Base Value & Standard Error & Source \\
\hline \multicolumn{5}{|c|}{ Transition probabilities } \\
\hline & From CHPS to Health Centre $-\mathrm{A}$ & 0.010 & 0.001 & DHIMS-2 \\
\hline & From Health Centre - A to Health Centre - B & 0.033 & 0.002 & DHIMS-2 \\
\hline & From Health Centre - B to Polyclinic & 0.028 & 0.002 & DHIMS-2 \\
\hline & From Polyclinic to Primary Hospital - A & 0.042 & 0.002 & DHIMS-2 \\
\hline & From Primary Hospital - A to Primary Hospital - B & 0.167 & 0.005 & DHIMS-2 \\
\hline & From Primary Hospital - B to Primary Hospital - C & 0.129 & 0.004 & DHIMS-2 \\
\hline & From Primary Hospital - C to Primary Hospital-D & 0.084 & 0.003 & DHIMS-2 \\
\hline & From Primary Hospital - D to Regional Hospital & 0.021 & 0.002 & DHIMS-2 \\
\hline & From Regional Hospital to EmTH & 0.091 & 0.003 & DHIMS-2 \\
\hline & From EmTH to EsTH & 0.001 & 0.000 & DHIMS-2 \\
\hline
\end{tabular}

Abbreviations: CBPS, community-based health planning and services; EmTH, emerging teaching hospital; EsTH, established teaching hospital; DHIMS-2, District Health Information Management System database.

used to compute the number of health facilities in each year. CHPS $_{i, j}=$ Population $_{i, j} / 1,500$ Eq. (I)

$\mathrm{HCA}_{i, j}=\left(\mathrm{HCA}_{i, j-1}-\left(\mathrm{HCA}_{\mathrm{i}, \mathrm{j}-1} *\right.\right.$ Transition Probability ${ }_{\text {HCA to }}$ $\left.\left.{ }_{H C B}\right)\right)+\left(\mathrm{CHPS}_{i, j-1} *\right.$ Transition Probability $\left.{ }_{\text {CHPS to } H C A}\right)+$ Newly constructed HC Eq. (II)

$\mathrm{HCB}_{i, j}=\left(\mathrm{HCB}_{i, j-1}-\left(\mathrm{HCB}_{\mathrm{i}, \mathrm{j}-1} *\right.\right.$ Transition Probability ${ }_{\text {HCB to }}$ $\left.\left.{ }_{P o l y C}\right)\right)+\left(\mathrm{HCA}_{i, j-1} *\right.$ Transition Probability $\left.{ }_{\mathrm{HCA} \text { to } \mathrm{HCB}}\right)$ Eq. (III)

PolyC $_{i, j}=\left(\right.$ PolyC $_{i, j-1}-\left(\right.$ PolyC $_{\mathrm{i}, \mathrm{j}-1} *$ Transition Probability $_{\text {PolyC }}$

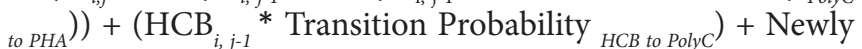
constructed PolyC Eq. (III)

$\mathrm{PHA}_{i, j}=\left(\mathrm{PHA}_{i, j-1}-\left(\mathrm{PHA}_{\mathrm{i}, \mathrm{j}-1} *\right.\right.$ Transition Probability $_{\text {PHA to }}$ $\left.\left.{ }_{P H B}\right)\right)+\left(\right.$ PolyC $_{i, j-1}^{i, j-1} *$ Transition Probability $\left.{ }_{\text {PolyC to } P H A}\right)+$ Newly constructed PHA Eq. (V)

$\mathrm{PHB}_{i, j}=\left(\mathrm{PHB}_{i, j-1}-\left(\mathrm{PHB}_{\mathrm{i}, \mathrm{j}-1} *\right.\right.$ Transition Probability $\left.\left.{ }_{\text {PHB to } P H C}\right)\right)$ $+\left(\mathrm{PHA}_{i, j-1}\right.$ * Transition Probability $\left.{ }_{\text {PHA to } P H B}\right)$ Eq. (VI)

$\mathrm{PHC}_{i, j}=\left(\mathrm{PHC}_{i, j-1}-\left(\mathrm{PHC}_{\mathrm{i}, \mathrm{j}-1} *\right.\right.$ Transition Probability $\left.\left.{ }_{\text {PHC to PHD }}\right)\right)$

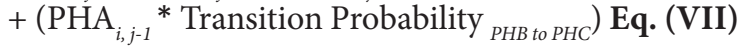

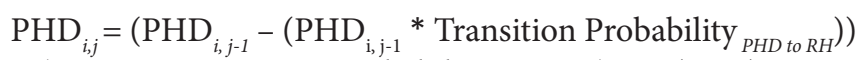
$+\left(\mathrm{PHC}_{i, j-1} *\right.$ Transition Probability $\left.{ }_{P H C \text { to } P H D}\right)$ Eq. (VIII)

$\mathrm{RH}_{i, j}=\left(\mathrm{RH}_{i, j-1}-\left(\mathrm{RH}_{\mathrm{i}, \mathrm{j}-1} *\right.\right.$ Transition Probability $\left.\left.{ }_{\mathrm{RH} \text { to EmTH }}\right)\right)+$ $\left(\mathrm{PHD}_{i, j-1} *\right.$ Transition Probability $\left.{ }_{P H D \text { to } R H}\right)+$ Newly constructed RH Eq. (IX)

$\mathrm{EmTH}_{i, j}=\left(\mathrm{EmTH}_{i, j-1}-\left(\mathrm{EmTH}_{\mathrm{i}, \mathrm{j}-1} *\right.\right.$ Transition Probability $_{\text {EmTH }}$ to EsTH $))+\left(\mathrm{RH}_{i, j-1}{ }^{*}\right.$ Transition Probability $\left.{ }_{R H \text { to EmTH }}\right)+$ Newly constructed EmTH Eq. (X)

EsTH $_{i, j}=\mathrm{EsTH}_{i, j-1}+\left(\mathrm{EmTH}_{i, j-1} *\right.$ Transition Probability EmTH to EsTH) Eq. (XI)

Where:

CHPS $_{i, j}$ represents the number of CHPS in administrative region $i$ at year $j$.

$\mathrm{J}-1$ represents the previous year.
Transition Probability ${ }_{H C A}$ to ${ }_{C B}$ represents the probability of Health Center A transitioning to Health Center B in a given year.

Similar notations apply to all the categories of healthcare facilities.

\section{Translating the Number of Healthcare Facilities Into HWF Requirements \\ Computing the Health Workforce Requirements}

To get the required HWF, the projected number of various categories of healthcare facilities in a particular year was multiplied by the appropriate staffing norm. This was then adjusted for workload changes. The HWF requirement was calculated using the following formula:

$H W F k_{i j}=\Sigma\left[\left(C H P S_{i j}{ }^{*} S S k_{C H P S}\right)+\left(H C A_{i j}{ }^{*} S S k_{H C A}\right)+\right.$

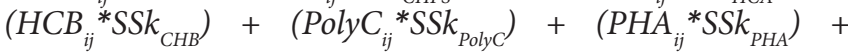
$\left(\mathrm{PHB}_{i j}{ }^{*} \mathrm{SSk}_{\mathrm{PHB}}\right)+\left(\mathrm{PHC}_{i j}{ }^{*} \mathrm{SSk}_{\mathrm{PHC}}\right)+\left(\mathrm{PHD}_{i j}{ }^{*} \mathrm{SSk}_{\mathrm{PHD}}\right)+$ $\left.\left(R H_{i j}{ }^{i j} S S k_{R H}\right)^{P H B}+\left(E m T H_{i j}{ }^{*} S S k_{E m T H}\right)+\left(E s T H_{i j}{ }^{*} S S k_{E s T H}\right)\right]$ Eq. (XII)

Where:

$\mathrm{HWFk}_{\mathrm{ij}}$ represents the base HWF requirement for a particular type of staff $k$ in administrative region $i$ at year $j$.

$S S k_{\text {CHPS }}$ represents the stipulated staffing standard for staff type $k$ at the CHPS level (similar notations apply to the other categories of healthcare facilities example, HCA, HCB etc.) CHPS $_{i \mathrm{ij}}$ represents total number of CHPS in region $i$ at year $j$. The adjusted HWF requirement for region $i$ at year $j$ (denoted $H W F_{i j a d j}$ ) take the form:

$H W F_{i j a d j}=\sum\left[H W F_{i j}+\left(H W F_{i j}{ }^{*} w c a\right)\right] \mathbf{E q} \cdot(\mathbf{X I I I})$

As stipulated by the $\mathrm{MoH}$ staffing norms, the base HWF requirement was adjusted for workload changes that require adjustments in staffing level (denoted $w c a$ ) but not significant to lead to a healthcare facility moving from one workload category to another.

The national HWF requirements then become a summation of the HWF requirements from all the ten political/ administrative regions of Ghana. 


\section{The Ghana Staffing Standards/Norms}

The staffing standards applied in the formulae above was taken from the $\mathrm{MoH}$ staffing norms for the health sector of Ghana, volume 1. ${ }^{26}$ Staffing standards define expected workload levels at various categories of health facilities, and the number of each cadre of health staff required in those healthcare facilities to deliver healthcare. The number of staff required in various health facilities as per the staffing norms is publicly available. ${ }^{27}$

The staffing norms ${ }^{26}$ also provide that when the workload in a health facility changes beyond $5 \%$ but the change is not sufficient to cause a transition of a health facility from one category of HWF requirement to another, the following guide should be used for adjustments.

- $15 \%$ or more change in workload would lead to about $23.5 \%$ adjustments in staff requirement [however, workload changes beyond $15 \%$ require a thorough assessment of the status of the health facility].

- Above $10 \%$ but less than $15 \%$ change in workload would lead to about $14.3 \%$ adjustment in staff requirement.

- $5 \%$ up to $10 \%$ change in workload would lead to about $6.3 \%$ adjustment in staff requirement.

- Less than $5 \%$ change in workload does not merit adjustment in staff requirement.

The aforesaid policy guide was incorporated in the model.

\section{Determining Existing Staff-Availability Gaps}

To determine the existing level of HWF needs-availability gaps, a ratio of the current staffing levels to the projected requirement was made (referred to as staff-availability ratio, SAR). Two forms of HWF gap analysis can be distinguished. First, supply-side and demand-side HWF forecasts can be compared to establish the existence or otherwise of labour market equilibrium or supply-and-demand gap. ${ }^{36}$ This is often useful for planning training and development programmes. The second, known as the HWF needs-availability gap where existing staffing levels (those employed) are compared with projected needs is applied in this study. This type of gap analysis is useful for recruitment and deployment planning as well as wage bill management.?

\section{Sensitivity Analysis}

Uncertainty around the point estimates of HWF requirements arising from parameter uncertainty, particularly the transition probabilities were explored by simultaneously varying all the transition probabilities in the predictive model using both their lower and upper 95\% confidence limits. Savelli and Joslyn $^{37}$ point out that "uncertainty can be expressed as a predictive interval, providing the upper and lower boundaries of a range within which the observed value is expected."

\section{Results}

Modelled Transitions of Health Facilities From One Category of Workload to the Other

Using equations II-XI, we modelled the expected transition of health facilities from one category the other (Table 2). The forecast shows marginal annual changes in the number of health facilities making transitions from one workload category to the other. Notably, only transitions from primary hospitals in workload categories A (PHA) to category B (PHB) is predicted to take place at a declining rate from 16 in 2016 to about 6 in 2026. In aggregate, over the next decade, it is expected that about 637 CHPS will likely transition to health centre within workload category A (HCA) while some 369 HCA will also transition to HCB but only 89 HCBs are expected to move to become Polyclinics (PolyC) within the next decade. Also, a near equilibrium is expected between the number of health facilities transitioning from PHD to $\mathrm{RH}$ and those from RH to EmTH.

Healthcare Facilities (Service Development) Forecast Overall, the forecast shows the need for an increase of about $45 \%$ in the aggregate number of healthcare facilities from 5749 at baseline to 8326 by 2026 (Table 3). Such steady increase in the number of healthcare facilities is predicted across all the categories of healthcare facilities except RHs and primary

Table 2. Modelled Transitions From One Category of Health Facility to Another

\begin{tabular}{|c|c|c|c|c|c|c|c|c|c|c|}
\hline Year & $\begin{array}{c}\text { CHPS to } \\
\text { HCA }\end{array}$ & $\begin{array}{c}\text { HCA to } \\
\text { HCB }\end{array}$ & $\begin{array}{c}\text { HCB to } \\
\text { PolyC }\end{array}$ & $\begin{array}{c}\text { PolyC to } \\
\text { PHA }\end{array}$ & PHA to PHB & $\begin{array}{c}\text { PHB to } \\
\text { PHC }\end{array}$ & $\begin{array}{c}\text { PHC to } \\
\text { PHD }\end{array}$ & $\begin{array}{c}\text { PHD to } \\
\text { RH }\end{array}$ & $\begin{array}{l}\text { RH to } \\
\text { EmTH }\end{array}$ & $\begin{array}{c}\text { EmTH to } \\
\text { EsTH }\end{array}$ \\
\hline 2016 & 45.6 & 29.5 & 4.5 & 1.7 & 16.0 & 6.3 & 2.4 & 0.3 & 0.6 & - \\
\hline 2017 & 48.8 & 30.4 & 5.2 & 2.0 & 14.4 & 7.6 & 2.8 & 0.3 & 0.6 & - \\
\hline 2018 & 52.1 & 31.1 & 5.9 & 2.3 & 13.0 & 8.4 & 3.2 & 0.4 & 0.7 & - \\
\hline 2019 & 55.4 & 31.8 & 6.6 & 2.7 & 11.8 & 9.0 & 3.6 & 0.4 & 0.6 & \\
\hline 2020 & 58.7 & 32.6 & 7.3 & 2.9 & 10.4 & 9.4 & 4.1 & 0.5 & 0.6 & - \\
\hline 2022 & 60.9 & 34.3 & 8.8 & 3.3 & 8.2 & 9.5 & 4.9 & 0.7 & 0.6 & - \\
\hline 2023 & 62.0 & 35.2 & 9.5 & 3.5 & 7.3 & 9.3 & 5.3 & 0.8 & 0.6 & - \\
\hline 2024 & 63.2 & 36.0 & 10.2 & 3.8 & 6.7 & 9.1 & 5.7 & 0.9 & 0.6 & - \\
\hline 2025 & 64.4 & 36.9 & 10.9 & 4.0 & 6.2 & 8.8 & 5.9 & 1.0 & 0.7 & - \\
\hline 2026 & 65.6 & 37.8 & 11.7 & 4.3 & 5.9 & 8.4 & 6.2 & 1.1 & 0.7 & - \\
\hline $\begin{array}{l}\text { Total Number } \\
\text { of transitions }\end{array}$ & 637 & 369 & 89 & 34 & 109 & 95 & 49 & 7 & 7 & \\
\hline
\end{tabular}

Abbreviations: CHPS, community-based health planning and services; HCA, health centre in workload category A; HCB, health centre in workload category $\mathrm{B}$; PolyC, polyclinic; PHA, primary hospital in workload category A; PHB, primary hospital in workload category B; PHC, primary hospital in workload category C; PHD, primary hospital in workload category $\mathrm{D}$; $\mathrm{RH}$, regional hospital; EmTH, emerging teaching hospital; EsTH, established teaching hospital. 
Table 3. Healthcare Facilities (Categories and Number), 2017-2026

\begin{tabular}{|c|c|c|c|c|c|c|c|c|c|c|c|}
\hline Health Facility Type/Year & Baseline (2016) & 2017 & 2018 & 2019 & 2020 & 2021 & 2022 & 2023 & 2024 & 2025 & 2026 \\
\hline CHPS & 4449 & 4768 & 5088 & 5409 & 5731 & 5835 & 5943 & 6054 & 6169 & 6287 & 6409 \\
\hline HCA & 903 & 930 & 953 & 975 & 998 & 1024 & 1051 & 1077 & 1104 & 1131 & 1159 \\
\hline $\mathrm{HCB}$ & 158 & 183 & 208 & 233 & 259 & 284 & 309 & 335 & 360 & 386 & 412 \\
\hline PolyC & 40 & 48 & 56 & 66 & 69 & 74 & 79 & 84 & 90 & 97 & 103 \\
\hline PHA & 96 & 87 & 78 & 71 & 63 & 55 & 49 & 44 & 40 & 37 & 35 \\
\hline PHB & 49 & 59 & 66 & 70 & 73 & 74 & 74 & 72 & 70 & 68 & 65 \\
\hline $\mathrm{PHC}$ & 29 & 33 & 38 & 43 & 48 & 54 & 59 & 63 & 67 & 71 & 73 \\
\hline PHD & 14 & 16 & 19 & 21 & 25 & 28 & 32 & 36 & 41 & 46 & 51 \\
\hline $\mathrm{RH}$ & 7 & 7 & 7 & 7 & 7 & 7 & 7 & 7 & 7 & 7 & 7 \\
\hline EmTH & 2 & 3 & 3 & 4 & 4 & 4 & 5 & 5 & 6 & 7 & 7 \\
\hline EsTH & 2 & 2 & 2 & 2 & 3 & 3 & 3 & 3 & 3 & 3 & 3 \\
\hline Total Number of Primary (District) Hospitals & 188 & 194 & 200 & 205 & 208 & 211 & 213 & 216 & 219 & 222 & 225 \\
\hline Total Number of Health Facilities & 5749 & 6135 & 6518 & 6901 & 7279 & 7442 & 7610 & 7782 & 7958 & 8140 & 8326 \\
\hline
\end{tabular}

Abbreviations: CHPS, community-based health planning and services; $\mathrm{HCA}$, health centre in workload category $\mathrm{A}$; HCB, health centre in workload category B; PolyC, polyclinic; PHA, primary hospital in workload category A; PHB, primary hospital in workload category B; PHC, primary hospital in workload category C; PHD, primary hospital in workload category $\mathrm{D}$; $\mathrm{RH}$, regional hospital; EmTH, emerging teaching hospital; EsTH, established teaching hospital.

hospitals in workload categories A and B (PHA and PHB). In particular, the predicted number of PHAs tends to decrease steadily from 96 at baseline (2016) to 35 by 2026 because their workload is expected to increase whereby many of them would expand and move into the next higher category (PHB). Consequently, the number of primary hospitals in workload category $\mathrm{B}(\mathrm{PHB})$ is predicted to steadily increase from a baseline total of 49 and reach a peak of 74 by the fifth and sixth year (2021/2022), and thereafter, decline marginally (7\%) to 65 by the year 2026 as they expand and move into category $\mathrm{C}(\mathrm{PHC})$. However, the total number of primary hospitals is expected to increase by $20 \%$ from 188 in 2016 to 225 by the year 2026. This would potentially enable the attainment of a primary hospital in each district as may be necessary for UHC.

On the other hand, the forecasts show that RHs are expected to remain at a total of 7 throughout the forecast period mainly because the number of hospitals moving into that category tends to be similar to those expected to be developed and re-designated as emerging teaching hospitals (EmTHs). Consequently, the number of EmTHs is predicted to increase from 2 at baseline to 7 by 2026 (about a 250\% increase) whereas established teaching hospitals (EsTHs) would increase from 2 to 3 during the same period. Thus, the forecast shows a need to have a total of 10 teaching hospitals (EmTH and EsTH) by 2026, potentially one for each of the 10 political/ administrative regions.

Forecast of Aggregate HWF Requirements and Existing StaffAvailability Gaps

Generally, the results show a steady increase in HWF requirements across staff types are required to enable effective healthcare delivery in the public healthcare facilities (see Table 4 for the aggregate HWF requirements). Also, the forecast of the HWF requirements at the sub-national level was conducted for all the ten regions of Ghana (see Supplementary file 1 - Tables S1-S10). We also compared the existing number of staff employed by the $\mathrm{MoH}$ (current staffing levels) as a proportion of the projected requirements. The resulting SARs are presented in Figure 3. In general, the average SAR (as of March 2016) was 68\% but ranges widely from $15 \%$ to $94 \%$ across various staff types. Nine out of the 23 (39\%) staff types considered in the forecast have SAR between $50 \%$ and $69 \%$ whilst only four (17\%), including community health nurse, enrolled nurse, ophthalmic nurse, and physician assistant-anaesthesia are $70 \%$ or more. Conversely, the SAR of majority (10 out of 23 ) or $44 \%$ of the staff types are less than $50 \%$ and are considered to be in severe shortage.

\section{Sensitivity Analysis}

As described in the method section, uncertainties around the base estimates in HWF requirements were characterised in the form of predictive intervals which provides a plausible range within which we are $95 \%$ confident the true value would lie (see Table 5). The results show narrow predictive intervals, suggesting only minimal-to-moderate level of uncertainty within the forecast.

\section{Discussion \\ Number of Healthcare Facilities}

The forecast shows a need to expand the number and/ or capacity of existing healthcare facilities to cope with the expanding service delivery coverage and population increases if Ghana is to achieve its aim of UHC by $2020 .{ }^{15} \mathrm{UHC}$ is defined in terms of all people obtaining a range of promotive, preventive, curative, rehabilitative and palliative services 


\begin{tabular}{|c|c|c|c|c|c|c|c|c|c|c|c|c|}
\hline \multirow{2}{*}{ No. } & \multirow{2}{*}{ Staff Type } & \multicolumn{11}{|c|}{ Aggregate HWF Requirement for the Year } \\
\hline & & 2016 & 2017 & 2018 & 2019 & 2020 & 2021 & 2022 & 2023 & 2024 & 2025 & 2026 \\
\hline 1 & Biomedical scientist & 1392 & 1548 & 1719 & 1894 & 2146 & 2313 & 2488 & 2670 & 2861 & 2933 & 3006 \\
\hline 2 & Community health nurse & 17559 & 19441 & 21380 & 23432 & 25506 & 27062 & 28678 & 30355 & 32095 & 32911 & 33728 \\
\hline 3 & Critical care nurse & 1375 & 1537 & 1717 & 1901 & 2215 & 2407 & 2607 & 2817 & 3038 & 3115 & 3192 \\
\hline 4 & Dental surgeon & 237 & 254 & 273 & 289 & 305 & 321 & 339 & 357 & 377 & 386 & 396 \\
\hline 5 & Emergency nurse & 1145 & 1279 & 1435 & 1590 & 1804 & 1967 & 2139 & 2321 & 2511 & 2575 & 2639 \\
\hline 7 & Family medicine physician & 251 & 268 & 287 & 303 & 323 & 337 & 352 & 367 & 384 & 394 & 404 \\
\hline 8 & General surgeon & 280 & 301 & 326 & 348 & 377 & 399 & 422 & 447 & 474 & 486 & 498 \\
\hline 9 & Medical officer (general practitioner) & 3094 & 3434 & 3719 & 4194 & 4610 & 5004 & 5416 & 5846 & 6294 & 6454 & 6614 \\
\hline 10 & Mental health nurse & 2034 & 2236 & 2347 & 2659 & 2879 & 3098 & 3325 & 3560 & 3803 & 3900 & 3997 \\
\hline 11 & Midwife & 8816 & 9918 & 10886 & 12247 & 13554 & 14718 & 15906 & 17121 & 18365 & 18832 & 19299 \\
\hline 12 & Obstetrician \& gynaecologist & 490 & 547 & 611 & 673 & 750 & 814 & 880 & 948 & 1018 & 1044 & 1070 \\
\hline 14 & Ophthalmologist & 85 & 95 & 111 & 125 & 147 & 164 & 183 & 202 & 222 & 228 & 233 \\
\hline 15 & Paediatrician & 444 & 496 & 553 & 609 & 675 & 731 & 788 & 846 & 906 & 929 & 952 \\
\hline 16 & Pharmacist & 982 & 1089 & 1213 & 1334 & 1502 & 1620 & 1743 & 1871 & 2004 & 2055 & 2106 \\
\hline 17 & Pharmacy technician & 3640 & 4045 & 4368 & 4903 & 5360 & 5794 & 6244 & 6712 & 7197 & 7380 & 7563 \\
\hline 18 & Physician assistant (anaesthesia) & 759 & 836 & 929 & 1014 & 1108 & 1197 & 1290 & 1387 & 1489 & 1527 & 1565 \\
\hline 19 & Physician assistant (medical) & 2282 & 2539 & 2709 & 3087 & 3353 & 3633 & 3926 & 4233 & 4554 & 4670 & 4786 \\
\hline 20 & Public health nurse & 839 & 942 & 1055 & 1165 & 1271 & 1376 & 1483 & 1594 & 1708 & 1751 & 1795 \\
\hline 21 & Radiographer/x-ray technician & 719 & 798 & 885 & 971 & 1062 & 1141 & 1225 & 1311 & 1401 & 1437 & 1473 \\
\hline 22 & Registered general nurse & 21971 & 24477 & 26902 & 29888 & 33428 & 36119 & 38888 & 41744 & 44692 & 45829 & 46966 \\
\hline \multirow[t]{2}{*}{23} & Technical officer (laboratory) & 3501 & 3924 & 4369 & 4832 & 5235 & 5643 & 6068 & 6510 & 6968 & 7145 & 7322 \\
\hline & Total & 89644 & 99749 & 109545 & 121420 & 133686 & 143786 & 154217 & 164991 & 176125 & 180606 & 185087 \\
\hline
\end{tabular}

Abbreviation: HWF, health workforce. 


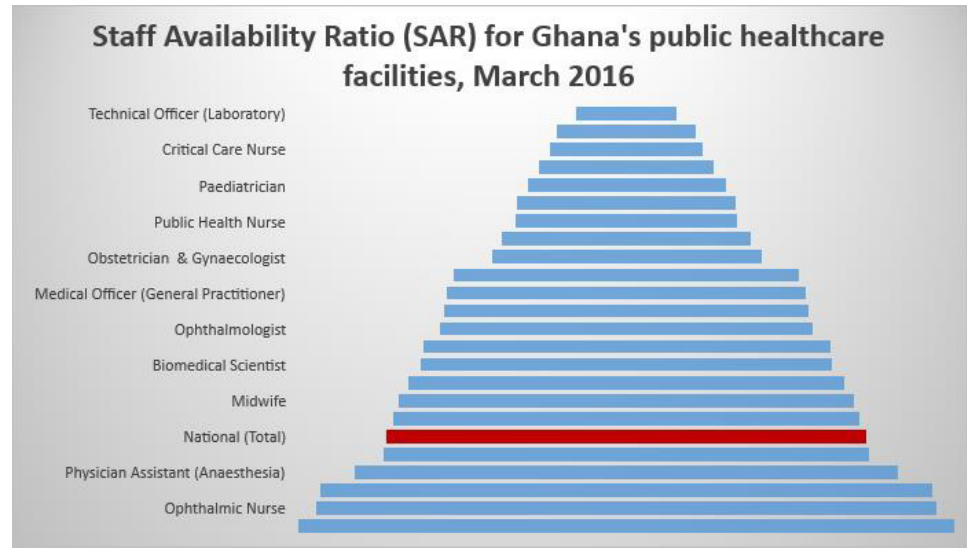

Figure 3. Staff-Availability Ratio (SAR) in Ascending Order of Existing Staffing Deficit (March 2016).

according to their needs, and without suffering financial hardship. ${ }^{38}$ This necessarily requires adequate provision of at least primary-level healthcare facilities including CHPS, HCs and DHs for communities, sub-districts and districts respectively. However, given the trend of health service utilisation and pace of service developments, this forecast shows it may take up to $2023 / 2024$ to achieve at least $216 \mathrm{DHs}$, potentially one for each of the 216 districts. Thus, under the aforesaid assumptions, the goal of attaining UHC by its true definition may only be feasible by 2023 onwards. In terms of financial protection for the poor, Ghana has made significant strides with a social health insurance coverage of $54 \%$ of its population (comprising $66 \%$ of the poor) ${ }^{22,39}$ However, inadequate healthcare infrastructure and human resources due to underinvestment in the health sector appear to be the key drawbacks to the attainment of UHC..$^{39}$ The government for instance, spent only $9.7 \%$ of its national budget on health ${ }^{39}$ against a target of $15 \% .{ }^{15,40}$ Of this, only $5 \%$ of the health budget was spent on capital and infrastructural investment whilst about $94 \%$ was spent on HWF salaries and emoluments. ${ }^{41}$ In contrast to a World Bank repor $\mathrm{t}^{17}$ suggesting there were more DHs in Ghana than required, this forecast has demonstrated a need for an increase. Using a WHO normative standard of one DH per 150000-250 000 population, and given Ghana's estimated population of 29422275 by 2017 , about 196 DHs would be needed. This is similar to the need for 194 predicted by this model. This not only underpins the validity of this model but also supports the need to equitably expand the healthcare infrastructure.

Indeed, the $\mathrm{MoH}$ in its capital investment plan has earmarked several health facilities to be upgraded while new ones of various types are at various stages of construction across the country. ${ }^{42}$ The projections in this paper suggests the need for the expansion of healthcare infrastructure although we acknowledge that these investments must be distributed equitably to ensure that no population groups are left behind in the efforts towards UHC.

HWF Requirements and Gaps

HWF shortages have been predicted and reported across Africa, ${ }^{19,21}$ resulting in various efforts to address it. Whilst
Ghana's efforts have yielded positive results, it continues to face significant HWF challenges. ${ }^{17,21}$ Compared with Scheffler and colleagues' estimates of HWF shortages by 2015, the current estimates are lower. Whilst this is attributable to fundamental differences in theoretical and methodological approaches, it is instructive to note that both models point to significant gaps in HWF availability in Ghana. Scheffler and colleagues assumed a normative standard of 0.55 doctors and 1.77 nurses and midwives per 1000 population across countries irrespective of infrastructural capacity and the influence of other local factors. Thus, it tends to yield high HWF estimates but also useful for comparison across countries.

This forecast shows an average SAR of $68 \%$, but the figure varies widely by staff type from $15 \%-94 \%$. Of 23 staff types considered, only four had a SAR of $70 \%$ or more, notably auxiliary nurses (enrolled nurses and community health nurses usually trained for 2 years). This is attributable to the government's deliberate policy to expand and liberalise the training of these categories of health workers. ${ }^{174,434}$ This has, however, created a seeming skill-mix distortion in the nursing workforce whereby in 2015 about $57.4 \%$ of the clinical nursing staff were auxiliary (enrolled nurses) as against a desired national standard of $40 \%{ }^{34}$ This forecast shows a ratio of $38 \%$ enrolled nurses to $62 \%$ professional nurses. A ratio of $30 \%: 70 \%$ is however recommended in the nursing literature. ${ }^{45}$ On the other hand, the SAR of most generalist health professionals were estimated to be below $70 \%$, a milestone required to attain and sustain essential service provision. However, beyond the general shortage of the essential health workers (doctors, nurses and midwives), a more serious shortage is observed among the specialised professionals. These include among others, emergency nurses, critical care nurses, paediatricians, obstetricians and gynaecologists, as well as family medicine physicians. Whereas the level of shortfall among these specialists is serious, it does not appear that the gaps can be filled in the short term as their training takes a minimum of 2-3 years, and the training institutions also have limited capacity to increase enrolments. Also, the limited availability of generalist professionals meant that not so many can be allowed to take up specialist training at one time. A similar phenomenon of specialist shortages 
95\% Predictive Interval by Year

\begin{tabular}{|c|c|c|c|c|c|c|c|c|c|c|c|c|c|c|c|c|c|c|c|c|c|}
\hline \multirow{3}{*}{ No. } & \multirow{3}{*}{ Type of Staff } & \\
\hline & & \multicolumn{2}{|c|}{2017} & \multicolumn{2}{|c|}{2018} & \multicolumn{2}{|c|}{2019} & \multicolumn{2}{|c|}{2020} & \multicolumn{2}{|c|}{2021} & \multicolumn{2}{|c|}{2022} & \multicolumn{2}{|c|}{2023} & \multicolumn{2}{|c|}{2024} & \multicolumn{2}{|c|}{2025} & \multicolumn{2}{|c|}{2026} \\
\hline & & Lower & Upper & Lower & Upper & Lower & Upper & Lower & Upper & Lower & Upper & Lower & Upper & Lower & Upper & Lower & Upper & Lower & Upper & Lower & Upper \\
\hline 1 & Biomedical scientist & 1542 & 1555 & 1706 & 1733 & 1872 & 1917 & 2023 & 2088 & 2177 & 2264 & 2337 & 2449 & 2503 & 2643 & 2676 & 2847 & 2744 & 2920 & 2812 & 2992 \\
\hline 2 & Community health nurse & 19397 & 19485 & 21295 & 21466 & 23285 & 23578 & 25286 & 25698 & 26777 & 27320 & 28323 & 29005 & 29925 & 30757 & 31584 & 32577 & 32388 & 33406 & 33192 & 34235 \\
\hline 3 & Critical care nurse & 1529 & 1544 & 1701 & 1732 & 1876 & 1927 & 2046 & 2119 & 2222 & 2320 & 2405 & 2531 & 2596 & 2753 & 2796 & 2987 & 2867 & 3063 & 2938 & 3139 \\
\hline 4 & Dental surgeon & 253 & 254 & 272 & 273 & 288 & 291 & 303 & 308 & 318 & 325 & 334 & 343 & 351 & 363 & 370 & 384 & 379 & 394 & 388 & 404 \\
\hline 5 & Emergency nurse & 1273 & 1284 & 1422 & 1447 & 1569 & 1611 & 1714 & 1774 & 1864 & 1946 & 2023 & 2128 & 2190 & 2321 & 2365 & 2525 & 2425 & 2589 & 2485 & 2653 \\
\hline 7 & Family medicine physician & 267 & 268 & 287 & 288 & 302 & 305 & 316 & 320 & 329 & 335 & 343 & 351 & 357 & 367 & 372 & 385 & 382 & 395 & 391 & 405 \\
\hline 8 & General surgeon & 300 & 302 & 325 & 327 & 346 & 350 & 366 & 373 & 386 & 396 & 408 & 421 & 430 & 448 & 455 & 476 & 466 & 488 & 478 & 501 \\
\hline 9 & $\begin{array}{l}\text { Medical officer (general } \\
\text { practitioner) }\end{array}$ & 3413 & 3456 & 3675 & 3764 & 4120 & 4267 & 4465 & 4673 & 4824 & 5100 & 5199 & 5547 & 5589 & 6015 & 5994 & 6503 & 6147 & 6668 & 6299 & 6834 \\
\hline 10 & Mental health nurse & 2219 & 2253 & 2312 & 2382 & 2601 & 2717 & 2788 & 2951 & 2980 & 3195 & 3179 & 3449 & 3385 & 3713 & 3597 & 3987 & 3688 & 4089 & 3780 & 4190 \\
\hline 11 & Midwife & 9854 & 9982 & 10756 & 11016 & 12040 & 12454 & 13099 & 13673 & 14172 & 14918 & 15264 & 16193 & 16378 & 17501 & 17513 & 18844 & 17959 & 19323 & 18405 & 19803 \\
\hline 12 & Obstetrician \& gynaecologist & 544 & 549 & 607 & 616 & 665 & 680 & 724 & 746 & 784 & 812 & 846 & 882 & 910 & 954 & 976 & 1028 & 1001 & 1054 & 1026 & 1081 \\
\hline 14 & Ophthalmologist & 95 & 96 & 109 & 112 & 123 & 128 & 138 & 145 & 155 & 163 & 172 & 183 & 190 & 203 & 209 & 224 & 214 & 230 & 220 & 236 \\
\hline 15 & Paediatrician & 494 & 498 & 549 & 557 & 602 & 615 & 655 & 673 & 708 & 731 & 762 & 791 & 817 & 852 & 873 & 914 & 895 & 938 & 917 & 961 \\
\hline 16 & Pharmacist & 1085 & 1094 & 1204 & 1223 & 1318 & 1349 & 1426 & 1470 & 1535 & 1594 & 1648 & 1724 & 1765 & 1859 & 1887 & 2001 & 1935 & 2052 & 1983 & 2103 \\
\hline 17 & Pharmacy technician & 4018 & 4072 & 4312 & 4423 & 4812 & 4994 & 5194 & 5452 & 5586 & 5926 & 5992 & 6420 & 6411 & 6934 & 6844 & 7469 & 7018 & 7659 & 7192 & 7849 \\
\hline 18 & $\begin{array}{l}\text { Physician assistant } \\
\text { (anaesthesia) }\end{array}$ & 834 & 839 & 922 & 935 & 1004 & 1024 & 1086 & 1115 & 1170 & 1209 & 1258 & 1307 & 1349 & 1410 & 1444 & 1518 & 1481 & 1556 & 1518 & 1595 \\
\hline 19 & Physician assistant (medical) & 2517 & 2560 & 2664 & 2754 & 3013 & 3161 & 3249 & 3459 & 3495 & 3773 & 3751 & 4103 & 4018 & 4449 & 4297 & 4813 & 4406 & 4935 & 4515 & 5058 \\
\hline 20 & Public health nurse & 938 & 945 & 1047 & 1063 & 1153 & 1178 & 1251 & 1287 & 1350 & 1397 & 1451 & 1511 & 1555 & 1628 & 1662 & 1749 & 1704 & 1794 & 1746 & 1838 \\
\hline 21 & Radiographer/x-ray technician & 796 & 801 & 879 & 891 & 961 & 981 & 1035 & 1064 & 1110 & 1148 & 1187 & 1236 & 1267 & 1329 & 1351 & 1426 & 1385 & 1462 & 1419 & 1499 \\
\hline 22 & Registered general nurse & 24345 & 24609 & 26630 & 27175 & 29450 & 30326 & 31892 & 33123 & 34365 & 35982 & 36901 & 38937 & 39505 & 41997 & 42183 & 45173 & 43256 & 46323 & 44329 & 47472 \\
\hline 23 & Technical officer (laboratory) & 3907 & 3940 & 4333 & 4406 & 4773 & 4891 & 5151 & 5320 & 5531 & 5758 & 5925 & 6217 & 6331 & 6695 & 6751 & 7193 & 6923 & 7376 & 7095 & 7559 \\
\hline & Total & 99297 & 100200 & 108621 & 110470 & 119917 & 122926 & 129970 & 134199 & 139362 & 144924 & 149033 & 156033 & 158994 & 167545 & 169255 & 179484 & 173561 & 184050 & 177867 & 188617 \\
\hline
\end{tabular}

Abbreviation: HRH, human resources for health.

1049 International Journal of Health Policy and Management, 2018, 7(11), 1040-1052 
have been reported in other countries such as Spain, Zambia and the United States among other, ${ }^{46-49}$ suggesting a global challenge.

The current forecast has also indicated a severe shortage of some para-clinical staff such as laboratory technicians (85\% shortfall), pharmacy technicians (75\% shortfall) and radiographers $(69 \%$ shortfall). However, these have not been given prominence in both the international and local literature, a situation which suggests why a seeming low level of priority is being given to the training of these professionals whose input to quality healthcare delivery is substantial.

\section{Policy Implications}

This study brings to light a number of policy issues. First, there is a need for the government to generally increase and sustain investments in the health sector in the medium-tolong. Significant part of this investment should focus on equitably establishing more health facilities and expanding some of the existing ones to address the growing population health needs towards UHC. Amidst fiscal constraints, the government needs to show greater commitment to the Abuja target of spending at least $15 \%$ of the annual national budget on healthcare. ${ }^{40}$

Similarly, there is the need to increase investment in the development, recruitment and retention of the requisite HWF, and ensure appropriate distribution of this investment, to provide the needed services in healthcare facilities. In this regard, the $\mathrm{MoH}$ and its service delivery agencies need to urgently define the HWF national priorities by developing a medium-to-long term recruitment, training and development plan for generalist and specialist health professionals. In so doing, attention should also be paid to the so-called neglected para-clinical professionals in short supply.

In the interim, $\mathrm{MoH}$ could consider employing graduate level prepared nurses, privately trained physician assistants, pharmacists and foreign trained medical officers who are paradoxically unemployed amidst the need for their services. Inefficiencies and low productivity have been reported among Ghanaian health workers. ${ }^{50,51}$ However, up to $20 \%$ reduction in shortages could be achieved by marginally increasing productivity or altering the staff skill-mix through tasksharing. ${ }^{21,52}$ Therefore, the $\mathrm{MoH}$ could embark on developing staff productivity improvement initiatives across health workers, and also explore viable task-sharing options.

\section{Strengths and Limitations}

This work appears to be one of the first attempts to empirically forecast the HWF need of a country based on the HeSDA approach and made use of service data from all healthcare facilities while incorporating existing health sector plans and policies. It also provided the first forecast of the healthcare facilities needed in Ghana over a 10-year horizon. Whereas the forecast provided is specific to Ghana, the model is adaptable to other settings and has relatively moderate data requirements as compared to other approaches.

However, some limitations are worth noting. First, the forecast is limited in scope as it focused on only publicly funded healthcare facilities (government and faith-based) and selected types of staff. The private and quasi-government healthcare facilities, $57 \%$ of which are located in Accra and Kumasi Metropolis, ${ }^{53}$ were not considered in the forecast due to data constraints. Thus, when interpreting or using the forecast, one must be reminded that it does not necessarily represent the comprehensive picture of Ghana's health sector.

Secondly, this is only the HWF demand forecast that did not include HWF supply analysis. Consequently, the gaps presented are not supply-and-demand gaps (labour market equilibrium) but those of the needed staff currently employed; these concepts have separate significance and have been distinguished in the methods section.

Finally, the DHIMS-2 database from which service data was extracted to derive transition probabilities still has some limitations in data quality (95\%) and completeness (99.5\%) even though timeliness of the data reporting is reportedly $100 \% .^{34}$ Thus, the point estimates must be regarded as ordered rough estimates. Therefore, the predictive intervals which account for these uncertainties should always be taken into consideration when using the forecast as a decision-making aid.

\section{Conclusion}

There is a need to expand and/or increase the number of healthcare facilities to facilitate the attainment of UHC. Given the pace of execution of government healthcare infrastructural projects and trends of healthcare utilisation, it is expected that the requisite healthcare infrastructure for UHC would be attained from 2023 onwards.

Ghana has an average of $68 \%$ of its HWF requirements, but there are serious shortages of the essential health professionals that are worse amongst the specialists' groups. Addressing this situation may require a substantial increase in government's expenditure on HWF in the short-to-medium term, a demand that may be difficult to meet due to fiscal constraints. Under the circumstances, recruitment of trained but unemployed health professionals, improving HWF productivity, and ensuring equitable distribution of existing HWF may be the immediate steps to take whilst a long-term commitment to comprehensively address HWF challenges, including recruitments, expansion and streamlining of HWF training, is pursued.

\section{Recommendations for Further Research}

In taking this work forward, it would be necessary to conduct a supply-side forecast to establish the health labour market (dis)equilibrium in the Ghanaian context to inform future training and development policies. Since supply-side HWF forecast was not considered here, HWF supply and demand gap analysis appears not feasible under the circumstances. However, on an annual basis, the existing staffing levels could be compared with the projected requirements to establish HWF need-availability gaps to facilitate recruitment, distribution, and redeployment planning.

To further strengthen the validity of the approach used, it would be useful to undertake the forecast with alternative approaches for comparison. This would not only enhance the quality of policy decisions but also enrich academic discourse 
and fill gaps in the literature.

Finally, the model has shown promise in forecasting HWF needs using data from Ghana but there is the need to adapt it for testing and use with data from other countries.

\section{Ethical issues}

The study did not involve human subjects. The first author is an authorised user of the DHIMS-2 and human resources databases in Ghana but additional permission was obtained from Ghana Health Service (GHS) to use aggregate data for the purpose of this forecast. In addition, care was taken to ensure anonymity such that no identifiable information of individual healthcare facility, patient or staff is reported.

\section{Competing interests}

Authors declare that they have no competing interests.

Authors' contributions

JAA, PMB, and RO conceived of the study. JAA undertook literature review, JAA, PMB, RO designed the methodology; JAA undertook the modelling under the guidance and supervision of PMB and RO. JAA, MMC, SAD, and EAO drafted the manuscript which all the authors critically reviewed. All authors approved the manuscript for publication.

\section{Authors' affiliations}

${ }^{1}$ Human Resources Division, Ghana Health Service, Accra, Ghana. ${ }^{2}$ Health Economics Unit, University of Birmingham, Birmingham, UK. ${ }^{3}$ World Health Organization (WHO), Accra, Ghana. ${ }^{4}$ Ministry of Health, Accra, Ghana.

\section{Supplementary files}

Supplementary file 1 contains Tables S1-S10.

\section{References}

1. Nino FS. Sustainable development goals - United Nations. United Nations Sustainable Development. http://www.un.org/ sustainabledevelopment/sustainable-development-goals/. Published 2015. Accessed July 9, 2016.

2. Lopes MA, Almeida AS, Almada-Lobo B. Handling healthcare workforce planning with care: where do we stand? Hum Resour Health. 2015;13:38. doi:10.1186/s12960-015-0028-0

3. World Health Organization. Global Strategy on Human Resources for Health: Workforce 2030. Geneva: World Health Organization; 2016.

4. O'Brien-Pallas L, Baumann A, Donner G, Murphy GT, LochhaasGerlach J, Luba M. Forecasting models for human resources in health care. J Adv Nurs. 2001;33(1):120-129.

5. Hornby P, Ray DK, Shipp PJ, Hall TL. Guidelines for health manpower planning: a course book. Geneva, Switzerland: World Health Organization; 1980.

6. Sharma K, Zodpey SP, Gaidhane A, Quazi SZ. Methodological issues in estimating and forecasting health manpower requirement. J Public Adm Policy Res. 2014;6(2):25-33. doi:10.5897/ JPAPR2011.067

7. Kolehmainen-Aitken RL. Human resources planning: issues and methods. Data for Decision Making Project, Department of Population and International Health, Harvard School of Public Health; 1993. http://www.harvardschoolofpublichealth.com/ihsg/ publications/pdf/No-1.PDF. Accessed June 3, 2016.

8. Roberfroid D, Leonard C, Stordeur S. Physician supply forecast: better than peering in a crystal ball? Hum Resour Health. 2009;7:10. doi:10.1186/1478-4491-7-10

9. Chilvers R. Planning Framework for Human Resources for Health for Maternal and Newborn Care. London School of Hygiene \& Tropical Medicine; 2014.

10. Wichit Srisuphan RN, Sirikanokwilai N. Supply and Requirement Projection of Professional Nurses in Thailand over the Next Two Decades (1995-2015 $\quad$ AD). http://www.who.int/entity/hrh/en/ HRDJ_2_3_05.pdf?ua=1. Published 1995. Accessed June 23, 2016

11. Hall TL, Mejia A. Health manpower planning: principles, methods, issues. Geneva: World Health Organization; 1978.
12. Fakhri A, Seyedin H, Daviaud E. A Combined Approach for Estimating Health Staff Requirements. Iran J Public Health. 2014;43(1):107-115.

13. Labelle R, Stoddart G, Rice T. A re-examination of the meaning and importance of supplier-induced demand. J Health Econ. 1994;13(3):347-368. doi:10.1016/0167-6296(94)90036-1

14. Ministry of Health. National Community-Based Health Planning and Services (CHPS) Policy: Accelerating attainment of Universal Health Coverage and bridging the access inequity gap. Ghana: Ministry of Health; 2015.

15. Ministry of Health. The Health Sector Medium-Term Development Plan, 2014 -2017. Ghana: Ministry of Health; 2014.

16. Ministry of Health. National Health Policy: Creating Wealth Through Health. Ghana: Ministry of Health; 2007.

17. Saleh K. The Health Sector in Ghana: A Comprehensive Assessment. Washington, DC: World Bank Publications; 2013.

18. World Health Organization. Equitable Access to Functional Health Workforce and Community Health Workers in the Africa Region [Internet]. Windhoek, Namibia: WHO Regional Forum on Strengthening Health Systems for the SDGs and UHC; 2016. http:// www.afro.who.int/index.

19. African Health Workforce Observatory. Human Resources for Health Country Profile. Ghana: African Health Workforce Observatory; 2010.

20. Asamani JA, Naab F, Ansah-Ofei AM. Leadership styles in nursing management: implications for staff outcomes. J Health Sci. 2016;6(1):23-36. doi:10.17532/jhsci.2016.266

21. Scheffler RM, Mahoney CB, Fulton BD, Dal Poz MR, Preker AS. Estimates of health care professional shortages in sub-Saharan Africa by 2015. Health Aff (Millwood). 2009;28(5):w849-862. doi:10.1377/hlthaff.28.5.w849

22. Ministry of Health. Holistic Assessment of the Health Sector Programme of Work 2015. Accra: Ministry of Health, Ghana; 2016.

23. Ministry of Health. Health Sector Holistic Assessment of the Health Sector Performance - 2015. Ghana; Ministry of Health; 2016.

24. Ministry of Health. Holistic Assessment of the Health Sector Programme of Work 2013. Accra: Ministry of Health, Ghana; 2014.

25. Ministry of Health. National Assessment for Emergency Obstetric and Newborn Care. Ghana: Ministry of Health; 2011.

26. Ministry of Health. Staffing Norms for the Health Sector of Ghana (Volume 1). Ghana: Ministry of Health; 2015

27. World Health Organization. Workload Indicators of Staffing Need (WISN): Selected Country Implementation Experiences. Human Resources for Health Observer Series. 2016. http://apps.who.int/ iris/bitstream/10665/205943/1/9789241510059 eng.pdf. Accessed June 12, 2016.

28. Barton P, Bryan S, Robinson S. Modelling in the economic evaluation of health care: selecting the appropriate approach. $J$ Health Serv Res Policy. 2004;9(2):110-118. doi:10.1258/135581904322987535

29. Briggs A, Sculpher M, Claxton K. Decision Modelling for Health Economic Evaluation. Oxford: Oxford University Press; 2006.

30. Ghana Health Service. Ghana Health Service Strategic Plan 2015 -2025 (Final Draft). Ghana Health Service; 2016.

31. Ministry of Health. District Health Information System 2. Centre for Health Information Management (CHIM) - Ministry of Health; 2016. https://dhims.chimgh.org/dhims/dhis-web-commons/security/login. action. Accessed May 25, 2016.

32. Barton P. Modelling for Health Economics. University of Birmingham; 2016.

33. Drummond MF, Sculpher MJ, Torrance GW, Stoddart GL. Methods for the Economic Evaluation of Health Care Programmes. 4th ed. Oxford: Oxford University Press; 2015.

34. Ghana Health Service. Annual Report - 2015. Accra: Ghana Health Service; 2016.

35. Ministry of Finance. The Budget Statement and Economic Policy of the Government of Ghana for the 2016 Financial Year Presented to Parliament. Government of Ghana: Ministry of Finance; 2015.

36. McPake B, Scott A, Edoka I. Analyzing Markets for Health Workers: Insights from Labor and Health Economics. Washington, DC: The World Bank; 2014.

37. Savelli S, Joslyn S. The Advantages of Predictive Interval Forecasts 
for Non-Expert Users and the Impact of Visualizations. Appl Cogn Psychol. 2013;27(4):527-541. doi:10.1002/acp.2932

38. Kieny MP, Evans DB. Universal health coverage. East Mediterr Health J. 2013;19(4):305-306.

39. Garshong B, Akazili J. Universal Health Coverage Assessment Ghana. http://funsalud.org.mx/gnhe/Documentos/UHCDay/ GNHE\%20UHC\%20assessment_Ghana.pdf. Published 2015. Accessed August 3, 2016.

40. World Health Organization. The Abuja declaration: ten years on. Geneva: World Health Organization. 2011;53.

41. Ministry of Health. End-Year Report on the Budget Statement and Economic Policy of the Republic of Ghana for The 2015 Financial Year. Government of Ghana: Ministry of Health; 2016.

42. Ministry of Health. Capital Investment Report. In Holistic Assement of Annual Programme of Work - 2015. Ghana: Ministry of Health; 2016.

43. Ministry of Health. Human Resource Policies and Strategies for the Health Sector, 2007-2011. Ghana: Ministry of Health; 2007.

44. Appiah-Denkyira E, Herbst $\mathrm{CH}$. Towards Interventions in Human Resources for Health in Ghana: Evidence for Health Workforce Planning and Results. Washington, DC: World Bank; 2013.

45. Cherry B, Jacob SR. Contemporary Nursing: Issues, Trends \& Management. 4th ed. St. Louis: Mosby Elsevier; 2008.

46. Barber P, Lopez-Valcarcel BG. Forecasting the need for medical specialists in Spain: application of a system dynamics model. Hum
Resour Health. 2010;8:24. doi:10.1186/1478-4491-8-24

47. Mitka M. Looming shortage of physicians raises concerns about access to care. JAMA. 2007;297(10):1045-1046. doi:10.1001/ jama.297.10.1045

48. Suwannakij T, Sirikanokwilai N, Wibulpolprasert S. Supply projection for physician in Thailand over the next 25 years (1996-2020 AD). Hum Resour Health. 1998;2:117-128.

49. Ferrinho P, Siziya S, Goma F, Dussault G. The human resource for health situation in Zambia: deficit and maldistribution. Hum Resour Health. 2011;9:30. doi:10.1186/1478-4491-9-30

50. Addai E, Bosomprah S. Health Workforce Productivity. Accra: Present Ministry of Health; 2007.

51. Asabir K, Witter S, Herbst CH, Dedzo KM. The Performance of Health Workers. In: Appiah-Denkyira E, Herbst CH, eds. Towards Interventions in Human Resources for Health in Ghana: Evidence for Health Workforce Planning and Results. Washington, DC: World Bank; 2013.

52. Birch S, Kephart G, Tomblin-Murphy G, O'Brien-Pallas L, Alder R, MacKenzie A. Human Resources Planning and the Production of Health: A Needs-Based Analytical Framework. Can Public Policy. 2007;33(1 Suppl ):S1-16. doi:10.3138/9R62-Q0V1-L188-1406

53. Amporfu E. Private hospital accreditation and inducement of care under the Ghanaian national insurance scheme. Health Econ Rev. 2011;1(1):13. doi:10.1186/2191-1991-1-13 